\title{
Event-based analysis of the association between alcohol use and unsafe sex in seven sub-Saharan African countries
}

\author{
Shireen Assaf ${ }^{1}$ and Lindsay Mallick ${ }^{2}$ \\ ${ }^{1}$ ICF, The Demographic and Health Surveys (DHS) Program, Rockville, MD, United States \\ ${ }^{2}$ Avenir Health, The Demographic and Health Surveys (DHS) Program, Rockville, MD, United States
}

\begin{abstract}
Aims: To examine the association between alcohol consumption at last sex and unsafe sex in seven countries in sub-Saharan Africa.

Design: Multivariable logistic regression of unsafe sex was performed using cross-sectional data with a stratified sample design from seven countries.

Setting: The study uses data from the Demographic and Health Surveys of Lesotho, Kenya, Mozambique, Swaziland, Uganda, Zambia, and Zimbabwe.

Participants: Men and women age 15-49 years with data available on alcohol consumption and who have had sex in the last 12 months were included in the analysis.

Measures: The main independent variable is alcohol consumption at last sex with a non-cohabiting partner.

Findings: The analysis has shown that alcohol consumption was a strong predictor of unsafe sex for all surveys except for women in Kenya. Age and number of sexual partners were also strong predictors of unsafe sex.

Conclusions: The findings indicate that there is a positive link between alcohol consumption and unsafe sex in all countries except for Kenya among women. The inconsistent finding in Kenya requires further study. One of the main limitations of the analysis is the low number of observations found for women and men who reported drinking at last sex with a non-cohabiting partner.
\end{abstract}

\section{Introduction}

Alcohol use contributes to disease and injury, including cancer, cardiovascular disease, liver cirrhosis, motor vehicle accidents, and epilepsy (Hahn, Woolf-King, \& Muyindike, 2011; Lim et al., 2013; Rehm et al., 2009; World Health Organization [WHO], 2014). In addition, studies have found associations between alcohol and HIV/AIDS (Baliunas, Rehm, Irving, \& Shuper, 2010; Hahn et al., 2011). This link between HIV infection and alcohol use is of particular concern in sub-Saharan Africa, where HIV prevalence is the highest in the world (Hahn et al., 2011). Several studies and review articles have found a relationship between alcohol consumption and risky sexual behaviors, including sex with multiple or casual partners, unprotected sex, transactional sex, and sexual coercion (Cooper, 2002; Fisher, Bang, \& Kapiga, 2007; Kalichman, Simbayi, Kaufman, Cain, \& Jooste, 2007; Leigh \& Stall, 1993; Woolf-King \& Maisto, 2011).
There appears to be no consensus on the pathway or nature of the relationship between alcohol use and sexual behavior, and studies have found that the relationship may be either causal or spurious (Cooper, 2002, 2006). A causal explanation is supported by the theory of alcohol myopia and the expectancy theory, which mainly describe the pharmacological or psychological mechanisms by which alcohol use leads to risky sexual behavior (Cooper, 2006; MacDonald, MacDonald, Zanna, \& Fong, 2000; Weinhardt \& Carey, 2000). Cooper (2006) also describes a reverse causal explanation in which individuals who want to engage in risky sex may use alcohol to facilitate their desire. Alternatively, a spurious or third-variable explanation describes the importance of individual variables, or between-person differences, such as personality traits, gender, or other attributes that directly affect risk-taking behavior (Cooper, 2002, 2006). In other words, coping mechanisms, risk-seeking behavior, or lifestyle could influence drinking, having risky sex, or both.

Correspondence: Shireen Assaf, Ph.D., ICF, The Demographic and Health Surveys (DHS) Program, 530 Gaither Road, Suite 500, Rockville MD 20850 USA.

Telephone: +1.301.572.0230. Email: Shireen.Assaf@icf.com

Financial support: USAID

Declaration of interest: The authors declare no competing interests

Keywords: condom use, risky sexual behavior, event-based, alcohol consumption at last sex, sub-Saharan Africa 
A longitudinal study on behaviors associated with discrete sexual events revealed that the majority of differences in risky behaviors were explained at the within-person level, or the variability that each individual person can have from one occasion or situation to the next (Cooper, 2010). For example, individuals may behave differently in one relationship than another or exhibit varying personality characteristics from day to day.

Review articles on the link between alcohol and risky sex have grouped studies into three main types: global association studies, situational association studies, and event-level studies (Cooper, 2002; Kalichman et al., 2007; Leigh \& Stall, 1993; Woolf-King \& Maisto, 2011). Global association studies examine whether a person who engages in one behavior (alcohol intake) is more likely to engage in another behavior (risky sexual activity, such as sex with multiple or casual partners and unsafe sex). These studies include examining the relationship between alcohol consumption and HIV or other STI status. Only two review articles focused on studies in sub-Saharan Africa (Kalichman et al., 2007; Woolf-King \& Maisto, 2011). However, all of these review articles found that the majority of global association studies support an association between history of alcohol use and several risky sexual behavior outcomes, including HIV and STI status. Cooper (2002), however, found an inconsistent relationship between alcohol consumption and protective behaviors such as condom use.

Situational association studies explore the link between risky sexual behavior and alcohol consumption that occurred during the same time (or situation), such as within the same day. Event-level studies explore the link that occurred during a specific occasion, such as the most recent sexual encounter. The findings from situational association studies support the findings of global association studies of an existing positive association between alcohol use and risky sexual behavior. However, the findings from eventlevel studies are mixed. Leigh and Stall (1993) found several studies that indicate no relationship between substance abuse (drugs or alcohol) and use of condoms or other contraceptives in recent encounters. Cooper (2002) found that drinking was strongly associated with decreased protective behaviors (e.g., condom use) among younger individuals at first intercourse. A review article of eventlevel studies in the United States (Weinhardt \& Carey, 2000) did not support a link between alcohol use and protective behaviors (such as condom use). Woolf-King and Maisto (2011) found two event-level studies, both in South Africa, which showed that alcohol consumption decreased the likelihood of condom use; however, only one of the studies found this association to be significant (though this study was specifically focused on HIVpositive men and therefore cannot be generalized to the public). An event-level study of countries in sub-Saharan Africa by Kiene and Subramanian (2013) found that among men in Southern Africa, being drunk before most recent sex had a negative effect on condom use with steady partners, but that the effect was only marginally significant for women. The study also found that South and East African men had increased odds of condom use during most recent sex with casual partners if they were drunk (Kiene \& Subramanian, 2013).

The conflicting findings in the literature on the link between alcohol consumption and risky behaviors (including unsafe sex) and protective behaviors, especially in event-level studies, highlight the need for more studies in this area. There are also very few event-level studies in this topic conducted in sub-Saharan Africa. The analysis explores the link between alcohol consumption and unsafe sex in sub-Saharan Africa using the event-based measure of alcohol consumption at last sex with a non-cohabiting partner. The study is not an event-level study in the traditional sense, as it does not follow respondents over time to ask about their behaviors. However, since the analysis focuses on one event, last sex with a noncohabiting partner, for both alcohol consumption and condom use, it can be considered an event-based study. This analysis originated from an earlier study by the same authors (Mallick \& Assaf, 2015) but with a focus on the event-based analysis. The interest here is to study whether there is a significant association between alcohol consumption at last sex and unsafe sex, and to observe whether this association is similar in all the countries in the analysis and between men and women.

\section{Method}

\section{Data}

Data from the Demographic and Health Surveys (DHS) and one AIDS Indicator Survey (AIS) in sub-Saharan African countries with high HIV prevalence were selected for analysis (Table 1). In addition, only surveys that included questions on alcohol consumption at last sex were used in the analysis. These included Kenya 2008-2009 DHS (men and women), Lesotho 2009 DHS (men only), Mozambique 2009 AIS (women only), Swaziland 2006-2007 DHS (men and women), Uganda 2011 AIS (women only), Zambia 2013-2014 DHS (men and women), and Zimbabwe 20052006 DHS (men and women). While surveys were conducted with women and men in Lesotho, Mozambique, and Uganda, the question on alcohol consumption at last sex was not asked for both men and women.

\section{Measures}

The main outcome of interest was unsafe sex, which we defined as sex within the last year with a non-cohabiting partner and without the use of a condom at last intercourse (Ezzati, 2004). This was constructed as a binary variable based on a series of questions that first assess whether a respondent has had sex in the twelve months preceding the survey. If so, the respondent was asked 1 ) when was the last time the respondent had sexual intercourse in the past year, 2) was a condom used at the time of the last sexual intercourse, and 3) what was the relationship to that person with whom the respondent had last sexual intercourse. We coded unsafe sex as (1) if the respondent had sex within the last year and the most recent sexual intercourse was both with a non-cohabiting partner and without the use of a condom. We coded all other responses, such as most recent. 
Table 1

HIV prevalence among men and women age 15-49 in sub-Saharan Africa, DHS surveys 2005-2014

\begin{tabular}{|c|c|c|c|c|}
\hline \multirow[b]{2}{*}{ Country and survey year } & \multicolumn{2}{|c|}{ Women } & \multicolumn{2}{|c|}{ Men } \\
\hline & HIV prevalence & Number of women & HIV prevalence & Number of men \\
\hline Kenya 2008-2009 & 8.0 & 3,641 & 4.3 & 3,066 \\
\hline Lesotho 2009 & 26.7 & 3,778 & 18.0 & 2,856 \\
\hline Mozambique 2009 & 13.1 & 5,229 & 9.2 & 3,832 \\
\hline Swaziland 2006-2007 & 31.1 & 4,424 & 19.7 & 3,763 \\
\hline Uganda 2011 & 8.3 & 10,883 & 6.1 & 8,673 \\
\hline Zambia 2013-2014 & 15.1 & 14,719 & 11.3 & 13,140 \\
\hline Zimbabwe 2005-2006 & 21.1 & 6,947 & 14.5 & 5,848 \\
\hline
\end{tabular}

Note: Figures in bold indicate population that was included in the regression analysis

sex was with a cohabiting partner, or most recent sex was with a non-cohabiting partner but with the use of a condom, as safe sex (0). A non-cohabiting partner includes any nonmarital partner that does not currently live with the respondent, such as boyfriend/girlfriend, casual acquaintance, or commercial sex worker. Other measures of risky sexual behavior were not possible for this analysis. For example, having multiple partners, sex with a casual acquaintance, and having transactional sex all have very low frequencies in the surveys of the selected countries, especially among women.

We also constructed the main independent variable of interest from the series of questions regarding the last sexual intercourse. Following the above questions, another survey question is posed, referring to the same "last sexual intercourse". It reads, "The last time you had sexual intercourse with [this] person, did you or this person drink alcohol?” The response options are: no, respondent drunk only, partner drunk only, both drunk, and neither drunk but consumed alcohol. Due to the low frequencies in selfreported alcohol consumption, especially in women, any response that indicated that the respondent consumed alcohol was combined (i.e., respondent drunk, both drunk, or neither drunk but consumed alcohol) and responses that indicated that the respondent did not consume alcohol were combined (i.e., answered no or partner drunk only). This independent variable was also only coded positively (1) if the respondent drank at last sex and last sex was with a non-cohabiting partner. All other responses were coded as (0), which included did not drink at last sex with a noncohabiting partner, and drank or did not drink with a cohabiting partner.

Because this variable links alcohol consumption directly with the same occasion as the outcome (last sexual intercourse) and with the same non-cohabiting partner, it allows for a type of event-level analysis of alcohol consumption and unsafe sex. However, the data is not event-level in the conventional sense, as it is not based on a longitudinal study that follows respondents over time to observe their behaviors. Therefore, the analysis can be described as event-based as it is looking at the behavior at the same event, the last sexual intercourse.
The remaining independent variables included in the analysis were respondent's age (15-24, 25-34, 35 and over); place of residence by wealth (urban, rural non-poor, rural poor); respondent's education level (none or primary, secondary or more); and total lifetime number of sexual partners (one, two, three, four or more for women, and one-two, three-four, five-six, seven or more for men). The residence-by-wealth variable was created because of the high correlation between the place of residence variable and the wealth index. All countries had very low frequencies for the urban poor category (urban residence combined with the three lowest quintiles of the wealth index). Therefore, the urban category combines urban poor and urban non-poor. Rural poor included respondents in a rural residence that are in the two lowest quintiles of the wealth index (poorest and poor), and rural non-poor included rural respondents in the three highest quintiles of the wealth index (middle, rich, and richer). Finally, due to the different distributions of lifetime number of sexual partners by gender, this variable was categorized differently for women and men. This variable was used to control for some amount of between-person variability in risky behaviors.

\section{Data Analysis}

Adjusted logistic regressions were performed for each country separately. The regressions included only men and women who had sex in the past 12 months and were age 15-49. A stratified sampling design was used, with the strata variable created from a combination of urban or rural residences and region for each country. All analyses were conducted with Stata/SE software, version 15.0.

\section{Results}

\section{Descriptive results}

Table 2 shows the variables used in the regression analysis of men or women age 15-49 who had sexual intercourse in the past 12 months. Men in Lesotho engaged in unsafe sex most commonly (21\%), followed by women in Swaziland (20\%) and men in Swaziland (17\%). Unsafe sex was lowest in Zimbabwe, among women (6\%) and men (9\%). 
Table 2

Variables used in the regression analyses for men or women age 15-49 who have had sexual intercourse in the past 12 months, DHS surveys in sub-Saharan Africa, 2005-2014

\begin{tabular}{|c|c|c|c|c|c|c|c|}
\hline & \multicolumn{2}{|c|}{ Kenya 2008-2009 } & \multirow{2}{*}{\multicolumn{2}{|c|}{$\begin{array}{c}\text { Lesotho } 2009 \\
\text { Men }\end{array}$}} & \multirow{2}{*}{$\begin{array}{c}\text { Mozambique } \\
2009 \\
\text { Women }\end{array}$} & \multicolumn{2}{|c|}{ Swaziland 2006-2007 } \\
\hline & Women & Men & & & & Women & Men \\
\hline \multicolumn{8}{|c|}{ Unsafe sex with last sex partner } \\
\hline Yes & $11.2(671)$ & $11.8(275)$ & \multicolumn{2}{|c|}{$21.1(477)$} & $14.5(1199)$ & $20.2(693)$ & $17.2(426)$ \\
\hline No & $88.8(5307)$ & $88.2(2048)$ & \multicolumn{2}{|c|}{$78.9(1780)$} & $85.5(7081)$ & $79.8(2745)$ & $82.8(2051)$ \\
\hline \multicolumn{8}{|c|}{ Alcohol consumption at last sex } \\
\hline Yes & $0.8(48)^{1}$ & $2.1(49)^{1}$ & \multicolumn{2}{|c|}{$5.2(117)$} & $0.9(76)$ & $0.6(21)^{1}$ & $5.2(128)$ \\
\hline No & $99.2(5933)$ & $97.9(2274)$ & \multicolumn{2}{|c|}{94.8 (2139) } & $99.1(8226)$ & $99.4(3420)$ & $94.8(2350)$ \\
\hline \multicolumn{8}{|l|}{ Age } \\
\hline $15-24$ & $29.5(1765)$ & $25.9(601)$ & \multicolumn{2}{|c|}{39.8 (899) } & $33.6(2788)$ & $37.3(1283)$ & $30.5(755)$ \\
\hline $25-34$ & 39.7 (2373) & $37.4(870)$ & \multicolumn{2}{|c|}{$33.8(763)$} & $34.7(2880)$ & $33.8(1165)$ & $37.0(918)$ \\
\hline $35+$ & $30.8(1843)$ & $36.7(853)$ & \multicolumn{2}{|c|}{39.8 (899) } & $31.7(2634)$ & 28.9 (994) & $32.5(805)$ \\
\hline \multicolumn{8}{|c|}{ Residence by wealth } \\
\hline Urban & $25.8(1545)$ & $30.5(708)$ & & 46) & 33.1 (2749) & 27.8 (957) & $35.2(873)$ \\
\hline Rural non-poor & 40.6 (2429) & 40.1 (932) & & 54) & 32.8 (2726) & 39.8 (1369) & 38.7 (959) \\
\hline Rural poor & 33.6 (2008) & $29.4(683)$ & & 57) & 34.1 (2827) & 32.4 (1115) & $26.1(646)$ \\
\hline Education level & & & & & & & \\
\hline None/primary & $67.7(4052)$ & 53.8 (1249) & & 384) & 81.5 (6767) & 42.1 (1448) & 39.5 (979) \\
\hline Secondary+ & 32.3 (1930) & 46.2 (1074) & & 73) & 18.5 (1535) & 57.9 (1993) & 60.5 (1498) \\
\hline Lifetime number & sexual partners ( & (women) & & & & & \\
\hline 1 & 42.5 (2519) & & & & 29.6 (2267) & 35.7 (1190) & \\
\hline 2 & $30.4(1800)$ & & & & 25.2 (1927) & 30.2 (1007) & \\
\hline 3 & 16.5 (978) & & & & 16.7 (1280) & $18.6(620)$ & \\
\hline $4+$ & 10.6 (627) & & & & 28.5 (2182) & $15.6(520)$ & \\
\hline Lifetime number & sexual partners ( & (men) & & & & & \\
\hline $1-2$ & & 28 (583) & & 78) & & & $21.8(501)$ \\
\hline $3-4$ & & 25.4 (529) & & 92) & & & $27.5(631)$ \\
\hline $5-6$ & & $17.8(371)$ & & 81) & & & $19.8(453)$ \\
\hline $7+$ & & 28.7 (596) & & 79) & & & $30.9(709)$ \\
\hline & Uganda 2011 & & Zambia & 3-2014 & & Zimbabwe 2005- & \\
\hline & Women & & Women & Men & & Women & \\
\hline Unsafe sex with la & sex partner & & & & & & \\
\hline Yes & 10.7 (1578) & & $10.9(1334)$ & 15.2 (1519) & & $6.0(353)$ & (385) \\
\hline No & 89.3 (13225) & & 89.1 (10909) & 84.8 (8506) & & 94.0 (5526) & (3996) \\
\hline Alcohol consumpt & at last sex & & & & & & \\
\hline Yes & $2.2(319)$ & & $1.0(123)$ & 4.1 (409) & & $0.5(31)^{1}$ & (158) \\
\hline No & 97.8 (14491) & & 99.0 (12129) & 95.9 (9618) & & 99.5 (5848) & (4228) \\
\hline Age & & & & & & & \\
\hline $15-24$ & 29.5 (4365) & & 30.5 (3737) & $26.5(2656)$ & & 34.7 (2039) & (1195) \\
\hline $25-34$ & 36.4 (5395) & & 38.9 (4772) & 35.5 (3561) & & 39.0 (2293) & (1751) \\
\hline $35+$ & 34.1 (5050) & & 30.5 (3743) & $38.0(3810)$ & & 26.3 (1547) & (1195) \\
\hline
\end{tabular}




\begin{tabular}{|c|c|c|c|c|c|}
\hline & \multirow{2}{*}{$\begin{array}{c}\text { Uganda } 2011 \\
\text { Women }\end{array}$} & \multicolumn{2}{|c|}{ Zambia 2013-2014 } & \multicolumn{2}{|c|}{ Zimbabwe 2005-2006 } \\
\hline & & Women & Men & Women & Men \\
\hline \multicolumn{6}{|c|}{ Residence by wealth } \\
\hline Urban & $19.7(2923)$ & $42.6(5218)$ & $42.9(4298)$ & $35.8(2107)$ & 41.0 (1798) \\
\hline Rural non-poor & $44.0(6515)$ & $21.3(2611)$ & $21.8(2191)$ & $26.7(1567)$ & 26.2 (1149) \\
\hline Rural poor & $36.3(5372)$ & $36.1(4424)$ & $35.3(3538)$ & $37.5(2205)$ & 32.7 (1435) \\
\hline \multicolumn{6}{|l|}{ Education level } \\
\hline None/primary & 70.5 (10448) & $60.7(7425)$ & 45.9 (4598) & $40.6(2389)$ & $28.6(1255)$ \\
\hline Secondary ${ }^{+}$ & $29.5(4363)$ & $39.8(4815)$ & $54.1(5424)$ & $59.4(3491)$ & $71.4(3127)$ \\
\hline \multicolumn{6}{|c|}{ Lifetime number of sexual partners (women) } \\
\hline 1 & $25(3602)$ & $44.8(5473)$ & & $66.8(3914)$ & \\
\hline 2 & 23.7 (3409) & 31.1 (3799) & & $20.8(1220)$ & \\
\hline 3 & $18.2(2617)$ & 14.8 (1813) & & $7.5(440)$ & \\
\hline $4+$ & 33.1 (4770) & 9.2 (1127) & & 4.9 (284) & \\
\hline \multicolumn{6}{|c|}{ Lifetime number of sexual partners (men) } \\
\hline $1-2$ & & & $26.8(2661)$ & & 33.7 (1447) \\
\hline $3-4$ & & & 31.1 (3095) & & $28.2(1211)$ \\
\hline $5-6$ & & & 18.5 (1842) & & 16.3 (699) \\
\hline $7+$ & & & $23.6(2346)$ & & $21.8(936)$ \\
\hline
\end{tabular}

Notes: 1 - Estimates are to be interpreted with caution as they are based on fewer than 50 cases.

\section{Figure 1}

Percentage HIV positive, percentage who had unsafe sex with last sex partner, and percentage who consumed alcohol at last sex with a non-cohabiting partner, DHS surveys in sub-Saharan Africa, 2005-2014

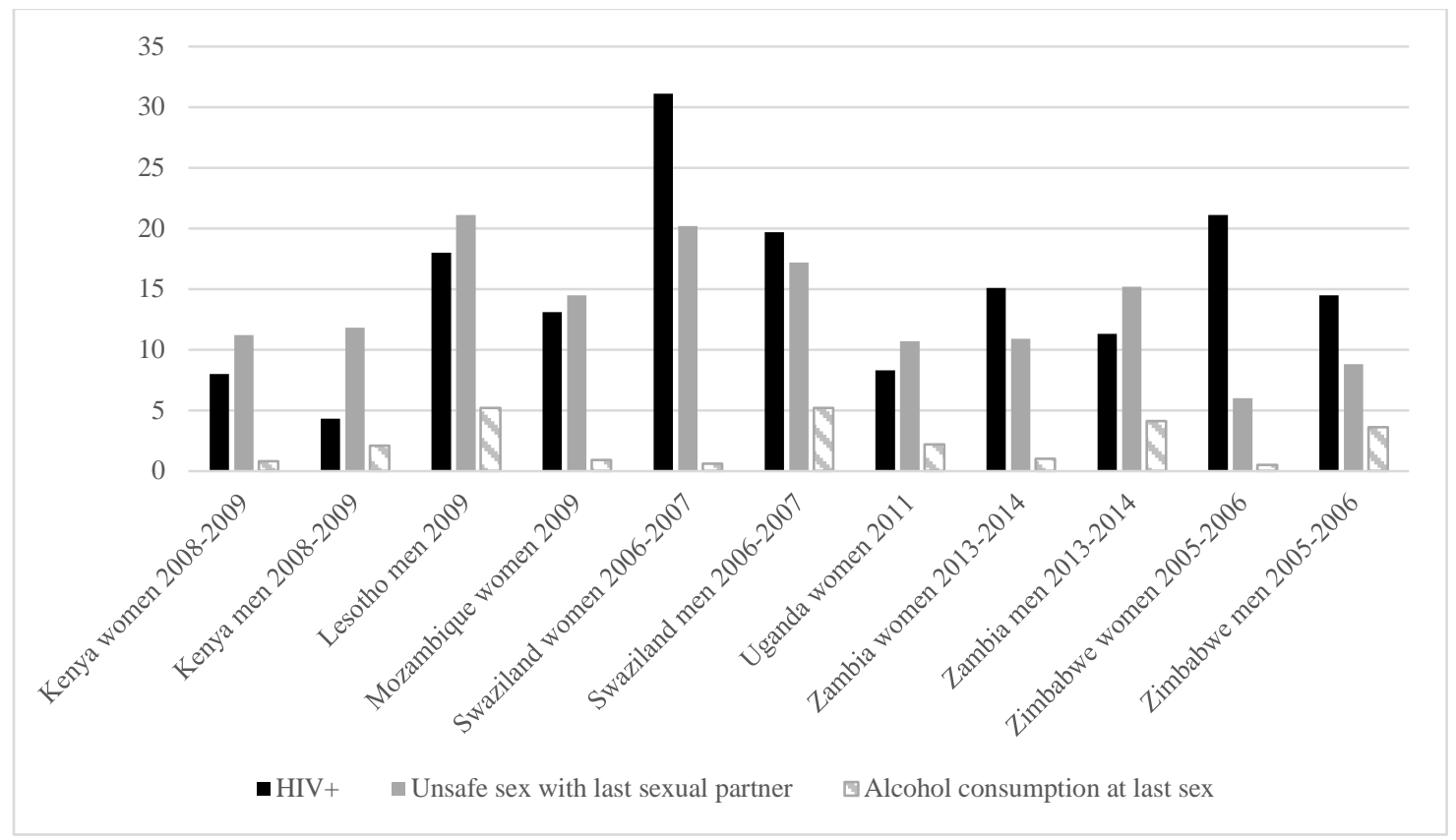

* HIV-positive estimates are for men or women aged 15-49 who were tested. The risky sexual behavior and alcohol consumption at last sex variables are for men or women aged 15-49 who have had sexual intercourse in the last 12 months. 
Men in Lesotho and Swaziland reported the highest proportion drinking alcohol at last sex with a noncohabiting partner (5.2\%); the highest among women was in Uganda (2.2\%). For countries where the question of drinking at last sex was asked of both men and women, men were more likely than women to report this behavior. In Kenya, Mozambique, Swaziland, Zambia, and Zimbabwe, the proportions of women who reported drinking at last sex were low (approximately 0.5-1.0\%), with some surveys having fewer than 50 cases. Figure 1 summarizes the DHS data on alcohol consumption, unsafe sex, and HIV-positive status in the sub-Saharan countries included in the analysis.

\section{Regression results}

Table 3 summarizes the adjusted logistic regressions for unsafe sex. The event-based analysis revealed that alcohol consumption at last sex was a significant predictor of unsafe sex for almost all populations. After adjusting for other variables, regression analysis found significant associations between alcohol at last sex and unsafe sex for all surveys except for women in Kenya. The results indicate that in these countries, respondents who drank at last sex with a non-cohabiting partner had higher odds of engaging in unsafe sex compared with respondents who did not drink at last sex with a non-cohabiting partner or had sex with a cohabiting partner. The odds ratios for this variable also had high magnitudes, with the lowest odds found in Zimbabwe men (OR 2.2, $p$.001) and odds ratios that were above 10 in women in Uganda and Zambia. It is important to note that due to the low number of cases found for those who drank at last sex with a non-cohabiting partner, the confidence intervals for these odds ratio had relatively large ranges. Due to the lack of data from women in Lesotho and Mozambique and men in Uganda, we cannot know the significance for this variable for both men and women in these countries.

Table 3

Adjusted (AD) Odds Ratios from the logistic regressions of unsafe sex for men and women age 15-49 who had intercourse in the past 12 months, DHS surveys in sub-Saharan Africa, 2005-2014

\begin{tabular}{|c|c|c|c|c|c|c|}
\hline & \multicolumn{2}{|c|}{ Kenya 2008-2009 } & \multirow{2}{*}{$\begin{array}{c}\text { Lesotho } 2009 \\
\text { Men }\end{array}$} & \multirow{2}{*}{$\begin{array}{c}\begin{array}{c}\text { Mozambique } \\
\text { 2009 }\end{array} \\
\text { Women } \\
\end{array}$} & \multicolumn{2}{|c|}{ Swaziland 2006-2007 } \\
\hline & Women & Men & & & Women & Men \\
\hline \multicolumn{7}{|c|}{ Alcohol consumption at last sex } \\
\hline Yes & 2.2 & $6.1^{* *}$ & $4.5^{* * *}$ & $5.4^{* * *}$ & $5.4^{* *}$ & $6.0 * * *$ \\
\hline No & Ref. & Ref. & Ref. & Ref. & Ref. & Ref. \\
\hline \multicolumn{7}{|l|}{ Age } \\
\hline $15-24$ & $3.4^{* * *}$ & $15.8^{* * *}$ & $3.9 * * *$ & $4.8^{* * *}$ & $4.6^{* * *}$ & $3.7 * * *$ \\
\hline $25-34$ & 1.1 & $3.5^{* * *}$ & 1.4 & 1.2 & $1.6^{* * *}$ & $1.7^{* *}$ \\
\hline $35+$ & Ref. & Ref. & Ref. & Ref. & Ref. & Ref. \\
\hline \multicolumn{7}{|l|}{ Locality by wealth } \\
\hline Urban & Ref. & Ref. & Ref. & Ref. & Ref. & Ref. \\
\hline Rural non-poor & $0.7^{*}$ & $1.7^{*}$ & $3.8^{* * *}$ & 0.9 & 1.2 & $1.4^{*}$ \\
\hline Rural poor & 0.8 & 1.0 & $4.2^{* * *}$ & $0.7 *$ & $1.3^{*}$ & $1.4^{*}$ \\
\hline \multicolumn{7}{|l|}{ Education level } \\
\hline None/primary & $0.7 * *$ & $1.8^{*}$ & $3.0^{* * *}$ & $1.3^{* *}$ & $1.2 *$ & $1.6^{* *}$ \\
\hline Secondary+ & Ref. & Ref. & Ref. & Ref. & Ref. & Ref. \\
\hline \multicolumn{7}{|c|}{ Lifetime of sexual partners (women) } \\
\hline 1 & Ref. & -- & -- & Ref. & Ref. & -- \\
\hline 2 & 1.3 & -- & -- & $2.4^{* * *}$ & 1.1 & -- \\
\hline 3 & $1.9 * * *$ & -- & -- & $3.1^{* * *}$ & $1.7 * * *$ & -- \\
\hline $4+$ & $3.6^{* * *}$ & -- & -- & $3.9 * * *$ & $2.2 * * *$ & -- \\
\hline \multicolumn{7}{|c|}{ Lifetime of sexual partners (men) } \\
\hline $1-2$ & -- & Ref. & Ref. & -- & -- & Ref. \\
\hline $3-4$ & -- & 0.7 & $1.5^{*}$ & -- & -- & 0.9 \\
\hline $5-6$ & -- & 0.6 & 1.4 & -- & -- & 1.1 \\
\hline $7+$ & -- & 1.1 & $1.6^{* *}$ & -- & -- & 1.1 \\
\hline Observations & 5,935 & 2,137 & 2,115 & 7,477 & 3,361 & 2,335 \\
\hline
\end{tabular}




\begin{tabular}{|c|c|c|c|c|c|}
\hline & \multirow{2}{*}{$\begin{array}{c}\text { Uganda } 2011 \\
\text { Women }\end{array}$} & \multicolumn{2}{|c|}{ Zambia 2013-2014 } & \multicolumn{2}{|c|}{ Zimbabwe 2005-2006 } \\
\hline & & Women & Men & Women & Men \\
\hline \multicolumn{6}{|c|}{ Alcohol consumption at last sex } \\
\hline Yes & $17.2^{* * *}$ & $11.0^{* *}$ & $5.3^{* * *}$ & $3.5^{*}$ & $2.2 * *$ \\
\hline No & Ref. & Ref. & Ref. & Ref. & Ref. \\
\hline \multicolumn{6}{|l|}{ Age } \\
\hline $15-24$ & $8.4^{* * *}$ & $5.9 * * *$ & $23.5 * * *$ & $3.0^{* * *}$ & $16.6^{* * *}$ \\
\hline $25-34$ & $1.5^{* * *}$ & 1.2 & $3.0^{* * *}$ & 0.8 & $2.3^{* * *}$ \\
\hline $35+$ & Ref. & Ref. & Ref. & Ref. & Ref. \\
\hline \multicolumn{6}{|l|}{ Locality by wealth } \\
\hline Urban & Ref. & Ref. & Ref. & Ref. & Ref. \\
\hline Rural non-poor & 1.0 & 1.0 & 1.1 & 0.8 & 1.2 \\
\hline Rural poor & $0.8^{* * *}$ & 1.0 & 0.9 & 0.8 & $2.1 * * *$ \\
\hline \multicolumn{6}{|l|}{ Education level } \\
\hline None/primary & $0.8^{* *}$ & $0.6^{* * *}$ & $1.3^{* *}$ & 0.9 & $1.8^{* * *}$ \\
\hline Secondary+ & Ref. & Ref. & Ref. & Ref. & Ref. \\
\hline \multicolumn{6}{|c|}{ Lifetime of sexual partners (women) } \\
\hline 1 & Ref. & Ref. & -- & Ref. & -- \\
\hline 2 & $1.3^{* *}$ & $1.5^{* * *}$ & -- & $3.6^{* * *}$ & -- \\
\hline 3 & $1.8^{* * *}$ & $2.7^{* * *}$ & -- & $6.9 * * *$ & -- \\
\hline $4+$ & $2.3^{* * *}$ & $4.0 * * *$ & -- & $9.7 * * *$ & -- \\
\hline \multicolumn{6}{|c|}{ Lifetime of sexual partners (men) } \\
\hline $1-2$ & -- & -- & Ref. & -- & Ref. \\
\hline $3-4$ & -- & -- & 1.2 & -- & 0.7 \\
\hline $5-6$ & -- & -- & $1.4 * * *$ & -- & 0.8 \\
\hline $7+$ & -- & -- & $1.5^{* * *}$ & -- & 1.3 \\
\hline Observations & 14,329 & 12,202 & 10,027 & 5,8223 & 4,222 \\
\hline
\end{tabular}

${ }^{*} p<.05,{ }^{* *} p<.01,{ }^{* * *} p<.001$

The age of respondent and lifetime number of sexual partners were also strong predictors of unsafe sex in all countries. This pattern was observed especially for the youngest age category (15-24) for both men and women, and for women who had four or more lifetime sexual partners. As Table 3 shows, respondents age 15-24 in every country had higher odds of engaging in unsafe sex compared with those age 35 and older. Among men, the odds ratio in Zambia was $233.5(p<.001)$, and in Kenya and Zimbabwe, it was between 16 and 17 ( $p<.001$ for both ORs). The odds ratios of women's lifetime number of sexual partners increased with increasing number of sexual partners. In all countries, the highest category of lifetime number of sexual partners (four or more) had significant odds ratios compared with women with one lifetime partner. The highest odds ratio for unsafe sex was found for women in Zimbabwe (OR 9.7, $p<.001)$. This predictor was not as strong for men and was not significant for men in Kenya, Swaziland, or Zimbabwe. However, men in Lesotho and Zambia who had seven or more lifetime partners had almost twice the odds of engaging in unsafe sex compared with men with one or two lifetime partners.

\section{Discussion}

The analysis presented showed that the association between alcohol consumption at last sex with a non-cohabiting partner and unsafe sex was found to be significant in all the surveys included in the analysis, except for the women survey in Kenya. Among three event-level studies carried out with data from sub-Saharan Africa, two found a significant association between alcohol consumption at last sex and unprotected sex (Kiene et al., 2008; Myer, Mathews, \& Little, 2002). However, these studies were conducted in South Africa and may not be generalizable to other sub-Saharan countries. In addition, the study by Kiene et al. (2008) only included participants who were HIV-positive, and therefore was not a sample of the general population. The lack of a consensus in the research 
regarding the link between alcohol consumption at last sex and unsafe sex perhaps supports a third-variable explanation (Cooper, 2002, 2006), which states that perhaps within-person variability is more important than between-person variability (Cooper, 2010). This may be the case in Kenya due to the inconsistent findings between the genders. However, the finding could also be an effect of one of the limitations of the study, such as the lower number of cases found for women who drank at last sex with a non-cohabiting partner. Therefore, further study is recommended to confirm these findings in Kenya.

Whether or not the partner has been drinking or is drunk may also have an effect on engaging in unsafe sex. The review of sub-Saharan African studies by Woolf-King and Maisto (2011) discusses the importance of the partner's role in unsafe sex, including partner drunkenness and partner type. These authors discuss qualitative studies that present the finding that women were forced to have sex after their partners returned home from drinking. This was also supported by a few of the quantitative studies in the review, such as in the event-level study by Kiene et al. (2008), which found that women had the highest odds for engaging in unprotected sex when the male partner had been drinking as compared to not drinking. Related findings were presented in other research (Kiene \& Subramanian, 2013; Tumwesigye, Wanyenze, \& Greenfield, 2012). Similar to the present analysis, Kiene and Subramanian (2013) found significant associations of alcohol consumption at last sex among men in Lesotho, Swaziland, and Zambia. When the variable for alcohol consumption at last sex with a non-cohabiting partner in the present analysis was reconstructed to match that in the Kiene and Subramanian (2013) study (i.e., male partner was drunk and female partner was not drunk, and they have a non-cohabiting relationship), the association with unsafe sex was still found for men in all the surveys in the analysis. Similarly, for women, the association with unsafe sex where the male partner was drunk and the female partner was not drunk during last sex with a non-cohabiting partner was significant for women in all surveys including Kenya (results not shown). Therefore, this implies that for women in Kenya, the drunkenness status of the male noncohabiting partner was more important than her own drinking status in terms of engaging in unsafe sex.

A major strength of DHS data is the standardization of core questionnaires and optional modules that allow for multicountry comparisons and trend analysis. The questions for alcohol consumption at last sex, as well as the questions used to construct the variables related to risky sexual behavior, were standardized questions in all the countries included in the analysis. However, there is a limitation that arises from the sensitive nature of these questions. Underreporting is common in the collection of survey data on alcohol consumption, as well as questions on sexual behaviors (Hahn et al., 2010; Minnis et al., 2009; Stockwell et al., 2004; Woolf-King \& Maisto, 2011). Stigma or social desirability bias may cause respondents to under-report alcohol use in order to present themselves more favorably to the interviewer (Bowling, 2005; Greenfield \& Kerr, 2008; Hahn et al., 2010; Hawkins et al., 2007). Under- reporting may be especially pertinent to women's selfreported data on behavior related to sexual risk-taking and alcohol use. A randomized control trial by Minnis et al. (2009) found that among HIV-negative women in Zimbabwe, there was a discrepancy in the biomarker measures of unprotected sex and self-reports of unprotected sex. Other studies address the same issue of underreporting of unsafe sex due to desirability bias (Gallo et al., 2006; Gallo et al., 2007). This under-reporting bias could also differ between countries due to different social norms and taboos. The small percentages and numbers of alcohol consumption at last sex with a non-cohabiting partner, especially for women and men in Kenya, and women in Swaziland and Zimbabwe, indicate that these findings should be interpreted with caution and further studies are required to confirm these results.

There is also a limitation from the lack of data for both genders for all the countries. Therefore, for Lesotho, Mozambique, and Uganda, we cannot say that the results found for these countries can be generalized to the whole population. It would have been particularly useful to conduct this analysis for Lesotho women where HIVpositive rates are higher compared to men.

Finally, due to the lack of information on the quantity of alcohol consumed for all the surveys, low and heavy episodic drinkers were combined together. The question on alcohol consumption did ask if the respondent or their partner was drunk; however, the categorization of "drunk" is a subjective term and a more quantifiable measure, such as units of alcohol consumed, could have strengthened the results.

While the findings for the association of alcohol consumption and unsafe sex were consistent for most surveys, the pathway of this relationship is still unknown. Research that is not cross-sectional in nature, such as qualitative research, may provide further insight on the relationship between alcohol use and unsafe sex.

\section{Acknowledgments}

The authors are grateful for the comments provided by Sarah Woolf-King on an earlier version of the paper.

\section{References}

Baliunas, D., Rehm, J., Irving, H., \& Shuper, P. (2010). Alcohol consumption and risk of incident human immunodeficiency virus infection: A meta-analysis. International Journal of Public Health, 55, 159-166.

Bowling, A. (2005). Mode of questionnaire administration can have serious effects on data quality. Journal of Public Health, 27, 281-291.

Cooper, M. L. (2002). Alcohol use and risky sexual behavior among college students and youth: Evaluating the evidence. Journal of Studies on Alcohol and Drugs, 101-117. 
Cooper, M. L. (2006). Does drinking promote risky sexual behavior? A complex answer to a simple question. Current Directions in Psychological Science, 15, 19 23.

Cooper, M. L. (2010). Toward a person x situation model of sexual risk-taking behaviors: Illuminating the conditional effects of traits across sexual situations and relationship contexts. Journal of Personality and Social Psychology, 98, 319-341.

Ezzati, M. (2004). Comparative quantification of health risks: Sexual and reproductive health (Vol. 2). Geneva, Switzerland: World Health Organization.

Fisher, J., Bang, H., \& Kapiga, S. (2007). The association between HIV infection and alcohol use: A systematic review and meta-analysis of African studies. Sexually Transmitted Diseases, 34, 856-863.

Gallo, M. F., Behets, F. M., Steiner, M. J., Hobbs, M. M., Hoke, T. H., Van Damme, K., . . . Cohen, M. S. (2006). Prostate-specific antigen to ascertain reliability of self-reported coital exposure to semen. Sexually Transmitted Diseases, 33, 476-479.

Gallo, M. F., Behets, F. M., Steiner, M. J., Thomsen, S., Ombidi, W., Luchters, S., . . . Hobbs, M. (2007). Validity of self-reported 'safe sex' among female sex workers in Mombasa, Kenya-PSA analysis. International Journal of STD \& AIDS, 18, 33-38.

Greenfield, T. K., \& Kerr, W. C. (2008). Alcohol measurement methodology in epidemiology: Recent advances and opportunities. Addiction, 103, 10821099.

Hahn, J. A., Bwana, M. B., Javors, M. A., Martin, J. N., Emenyonu, N. I., \& Bangsberg, D. R. (2010). Biomarker testing to estimate under-reported heavy alcohol consumption by persons with HIV initiating ART in Uganda. AIDS and Behavior, 14, 1265-1268.

Hahn, J. A., Woolf-King, S. E., \& Muyindike, W. (2011). Adding fuel to the fire: Alcohol's effect on the HIV epidemic in Sub-Saharan Africa. Current HIV/AIDS Reports, 8, 172-180.

Hawkins, E., Kivlahan, D., Williams, E., Wright, S., Craig, T., \& Bradley, K. (2007). Examining quality issues in alcohol misuse screening. Substance Abuse: Official Publication of the Association for Medical Education and Research in Substance Abuse, 28, 53-65.

Kalichman, S. C., Simbayi, L. C., Kaufman, M., Cain, D., \& Jooste, S. (2007). Alcohol use and sexual risks for HIV/AIDS in sub-Saharan Africa: Systematic review of empirical findings. Prevention Science, 8, 141-151.

Kiene, S. M., Simbayi, L. C., Abrams, A., Cloete, A., Tennen, H., \& Fisher, J. D. (2008). High rates of unprotected sex occurring among HIV-positive individuals in a daily diary study in South Africa: The role of alcohol use. Journal of Acquired Immune Deficiency Syndromes (1999), 49, 219-226.

Kiene, S. M., \& Subramanian, S. (2013). Event-level association between alcohol use and unprotected sex during last sex: Evidence from population-based surveys in sub-Saharan Africa. BMC Public Health, 13, 583.

Leigh, B. C., \& Stall, R. (1993). Substance use and risky sexual behavior for exposure to HIV: Issues in methodology, interpretation, and prevention. American Psychologist, 48, 1035-1045.

Lim, S. S., Vos, T., Flaxman, A. D., Danaei, G., Shibuya, K., Adair-Rohani, H., . . . Andrews, K. G. (2013). A comparative risk assessment of burden of disease and injury attributable to 67 risk factors and risk factor clusters in 21 regions, 1990-2010: A systematic analysis for the Global Burden of Disease Study 2010. The Lancet, 380, 2224-2260.

MacDonald, T. K., MacDonald, G., Zanna, M. P., \& Fong, G. (2000). Alcohol, sexual arousal, and intentions to use condoms in young men: Applying alcohol myopia theory to risky sexual behavior. Health Psychology, 19, 290-298.

Mallick, L., \& Assaf, S. (2015). An inventory of alcoholrelated questions in the Demographic and Health Surveys and an analysis of alcohol use and unsafe sex in sub-Saharan Africa. DHS Analytical Studies No. 53. Rockville, MD, United States: ICF International.

Minnis, A. M., Steiner, M. J., Gallo, M. F., Warner, L., Hobbs, M. M., Van der Straten, ... Padian, N. S. (2009). Biomarker validation of reports of recent sexual activity: Results of a randomized controlled study in Zimbabwe. American Journal of Epidemiology, 170, 918-924.

Myer, L., Mathews, C., \& Little, F. (2002). Condom use and sexual behaviors among individuals procuring free male condoms in South Africa: A prospective study. Sexually Transmitted Diseases, 29, 239-241.

Rehm, J., Mathers, C., Popova, S., Thavorncharoensap, M., Teerawattananon, Y., \& Patra, J. (2009). Global burden of disease and injury and economic cost attributable to alcohol use and alcohol-use disorders. The Lancet, 373, 2223-2233.

Stockwell, T., Donath, S., Cooper-Stanbury, M., Chikritzhs, T., Catalano, P., \& Mateo, C. (2004). Under-reporting of alcohol consumption in household surveys: A comparison of quantity-frequency, graduated-frequency and recent recall. Addiction, 99, 1024-1033.

Tumwesigye, N. M., Wanyenze, R. K., \& Greenfield, T. K. (2012). Intoxication before last sexual intercourse and HIV risk behavior among men and women in Uganda: Evidence from a nationwide survey. The International Journal of Alcohol and Drug Research, 1, 67-78.

Weinhardt, L. S., \& Carey, M. P. (2000). Does alcohol lead to sexual risk behavior? Findings from event-level research. Annual Review of Sex Research, 11, 125157.

World Health Organization. (2014). Global status report on alcohol and health-2014. Geneva, Switzerland: World Health Organization.

Woolf-King, S. E., \& Maisto, S. A. (2011). Alcohol use and high-risk sexual behavior in Sub-Saharan Africa: A narrative review. Archives of Sexual Behavior, 40, 17-42. 